\title{
The complexity of Orion: an ALMA view
}

\section{II. gGg'-ethylene glycol and acetic acid}

\author{
C. Favre ${ }^{1}$, L. Pagani ${ }^{2}$, P. F. Goldsmith ${ }^{3}$, E. A. Bergin ${ }^{4}$, M. Carvajal ${ }^{5,6}$, I. Kleiner ${ }^{7}$, G. Melnick ${ }^{8}$, and R. Snell ${ }^{9}$ \\ 1 INAF-Osservatorio Astrofisico di Arcetri, Largo E. Fermi 5, Firenze, 50125, Italy \\ e-mail: cfavre@arcetri.astro.it \\ 2 LERMA, UMR 8112 du CNRS, Observatoire de Paris, 61 Av. de l'Observatoire, 75014 Paris, France \\ 3 Jet Propulsion Laboratory, California Institute of Technology, 4800 Oak Grove Drive, Pasadena, CA 91109, USA \\ 4 Department of Astronomy, University of Michigan, 500 Church Street, Ann Arbor, MI 48109, USA \\ 5 Dpto. Ciencias Integradas, Unidad GIFMAN-UHU Asociada al CSIC, Universidad de Huelva, 21071 Huelva, Spain \\ 6 Instituto Universitario Carlos I de Física Teórica y Computacional, Universidad de Granada, Granada, Spain \\ 7 Laboratoire Interuniversitaire des Systèmes Atmosphériques (LISA), CNRS, UMR 7583, Université de Paris-Est et Paris Diderot, \\ 61, Av. du Général de Gaulle, 94010 Créteil Cedex, France \\ 8 Harvard-Smithsonian Center for Astrophysics, Cambridge, Massachusetts, USA \\ 9 Department of Astronomy, University of Massachusetts, Amherst, MA 01003, USA
}

Received 7 June 2017 / Accepted 5 July 2017

\begin{abstract}
We report the first detection and high angular resolution $\left(1.8^{\prime \prime} \times 1.1^{\prime \prime}\right)$ imaging of acetic acid $\left(\mathrm{CH}_{3} \mathrm{COOH}\right)$ and gGg'-ethylene glycol $\left(\mathrm{gGg}^{\prime}\left(\mathrm{CH}_{2} \mathrm{OH}\right)_{2}\right)$ toward the Orion Kleinmann-Low (Orion-KL) nebula. The observations were carried out at $\sim 1.3 \mathrm{~mm}$ with ALMA during Cycle 2. A notable result is that the spatial distribution of the acetic acid and ethylene glycol emission differs from that of the other O-bearing molecules within Orion-KL. While the typical emission of O-bearing species harbors a morphology associated with a V-shape linking the hot core region to the compact ridge (with an extension toward the BN object), the emission of acetic acid and ethylene glycol mainly peaks at about $2^{\prime \prime}$ southwest from the hot core region (near sources I and n). We find that the measured $\mathrm{CH}_{3} \mathrm{COOH}: \mathrm{aGg}^{\prime}\left(\mathrm{CH}_{2} \mathrm{OH}\right)_{2}$ and $\mathrm{CH}_{3} \mathrm{COOH}: \mathrm{gGg}^{\prime}\left(\mathrm{CH}_{2} \mathrm{OH}\right)_{2}$ ratios differ from those measured toward the low-mass protostar IRAS 16293-2422 by more than one order of magnitude. Our best hypothesis to explain these findings is that $\mathrm{CH}_{3} \mathrm{COOH} \mathrm{aGg}^{\prime}\left(\mathrm{CH}_{2} \mathrm{OH}\right)_{2}$, and $\mathrm{gGg}^{\prime}\left(\mathrm{CH}_{2} \mathrm{OH}\right)_{2}$ are formed on the icy surface of grains and are then released into the gas-phase via co-desorption with water, by way of a bullet of matter ejected during the explosive event that occurred in the heart of the nebula about 500-700 yr ago.
\end{abstract}

Key words. astrochemistry - ISM: molecules - radio lines: ISM

\section{Introduction}

The Orion Kleinmann-Low nebula (hereafter Orion-KL) is the high-mass star-forming region closest to Earth $(388 \pm 5 \mathrm{pc}$, Kounkel et al. 2017). Its proximity and rich molecular composition make this region well suited for astrochemical study. In this context, numerous single-dish surveys, including the broadband Herschel/HIFI HEXOS survey (Bergin et al. 2010; Crockett et al. 2014), as well as interferometric observations have been performed toward this region (e.g., Favre et al. 2015; Pagani et al. 2017, and references therein). It is important to note that two main molecular components are associated with Orion-KL: the compact ridge, and the hot core. The latter region may have resulted from interaction of the surrounding gas with remnants of the explosive event, triggered by the close encounter of the sources I, n, and the BN object, which occurred in the region about 500-700 yr ago (e.g., see Zapata et al. 2011; Nissen et al. 2012, and references therein). Thus, the complex physical structure and history make Orion-KL an interesting source that may not be representative of other high-mass star forming regions, however, to study the production route (at the icy surface of grains and/or in the gas phase) of complex organic molecules (i.e., molecules that contain six or more atoms, including carbon, hereafter COMs, see Herbst \& van Dishoeck 2009). Although present in other star-forming regions, some COMs have not yet been detected in Orion-KL. This is mainly due to sensitivity limitation and a high spectral confusion level (e.g., see Tercero et al. 2010). High resolution and sensitivity, as offered by ALMA, are thus mandatory to search for weak lines associated with COMs. In this context, we have used ALMA during Cycle 2 to perform deep observations of this region in a fraction of band $6(\approx 1-2 \mathrm{~mm})$.

Our ALMA Cycle 2 data and first results are given in a companion paper by Pagani et al. (2017, hereafter Paper I). In this Letter, we focus on acetic acid $\left(\mathrm{CH}_{3} \mathrm{COOH}\right)$ and the $\mathrm{gGg}^{\prime}$ conformer of ethylene glycol $\left(\mathrm{gGg}^{\prime}\left(\mathrm{CH}_{2} \mathrm{OH}\right)_{2}\right)$ and report their first detection in Orion-KL. The detection of acetic acid in OrionKL has not yet been reported, although a few transitions may be present in the IRAM $30 \mathrm{~m}$ survey by Tercero et al. (2011). However, this species is known to be present in low-mass and highmass star-forming regions (e.g., Remijan et al. 2003; Shiao et al. 2010; Jørgensen et al. 2016). Regarding gGg'-ethylene glycol, this conformer has only been detected toward the Class 0 protostar IRAS 16293-2422 by Jørgensen et al. (2016). Incidentally, the most stable conformer of ethylene glycol $\left(\mathrm{aGg}^{\prime}\right)$ is detected toward low-, intermediate-, and high-mass sources, including Orion-KL (see, e.g., Fuente et al. 2014; Lykke et al. 2015; Brouillet et al. 2015; Rivilla et al. 2017, and references therein). In Sect. 2 we briefly describe our ALMA observations. Results and analysis are given and discussed in Sects. 3 and 4, respectively. 

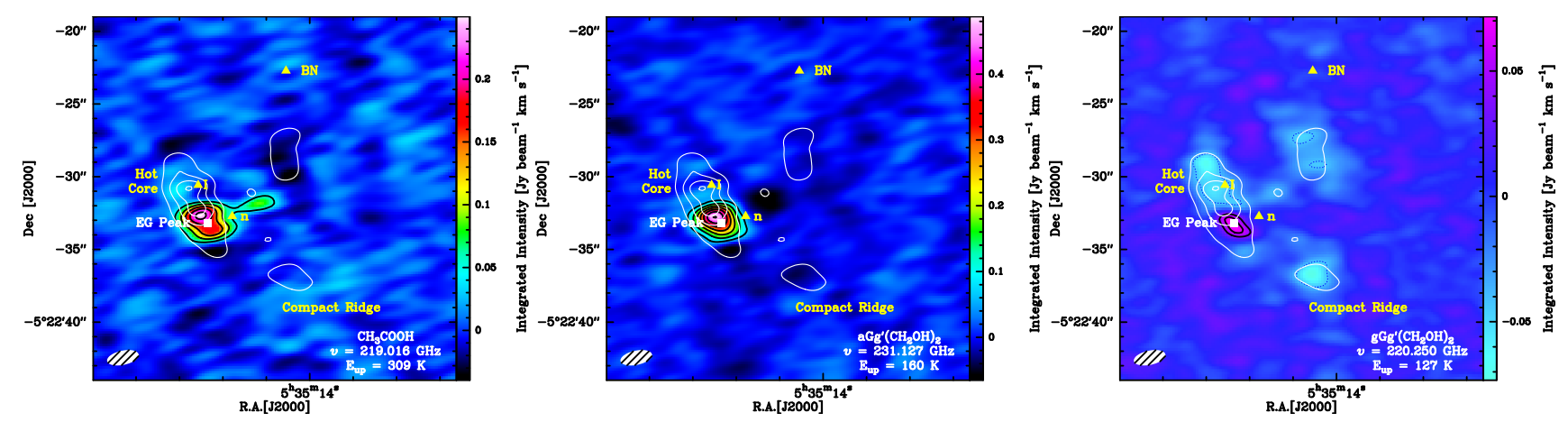

Fig. 1. Left panel: $\mathrm{CH}_{3} \mathrm{COOH}$ integrated emission map at $219016 \mathrm{MHz}$. The first contour and the level step are at $5 \sigma$ (where $1 \sigma=9.3 \times$ $\left.10^{-3} \mathrm{Jy} \mathrm{beam}^{-1} \mathrm{~km} \mathrm{~s}^{-1}\right)$. Middle panel: $\mathrm{aGg}^{\prime}\left(\mathrm{CH}_{2} \mathrm{OH}\right)_{2}$ integrated emission map at $231127 \mathrm{MHz}$. The first contour and the level step are at $5 \sigma$ (where $1 \sigma=1.4 \times 10^{-2} \mathrm{Jy}_{\text {beam }}{ }^{-1} \mathrm{~km} \mathrm{~s}^{-1}$ ). Right panel: $\mathrm{gGg}^{\prime}\left(\mathrm{CH}_{2} \mathrm{OH}\right)_{2}$ integrated emission map at $220250 \mathrm{MHz}$. The contour levels are at -4 , 4 , and $6 \sigma$ (where $1 \sigma=1 \times 10^{-2} \mathrm{Jy} \mathrm{beam}^{-1} \mathrm{~km} \mathrm{~s}^{-1}$ ). A narrow $v_{\mathrm{LSR}}$ interval (from 7 to $9 \mathrm{~km} \mathrm{~s}^{-1}$ ) has been selected to reduce confusion by nearby lines (see Sect. 3.3 and Appendix C). Positions of the radio source I, the BN object, and the IR source $\mathrm{n}$ (see Goddi et al. 2011) are indicated by yellow triangles. The white square indicates the position of the ethylene glycol peak $\left(\alpha_{J 2000}=05^{\mathrm{h}} 35^{\mathrm{m}} 14 \mathrm{~s}^{\mathrm{s}} 47, \delta_{J 2000}=-05^{\circ} 22^{\prime} 33^{\prime \prime}\right.$. 17$)$ by BD15. Finally, the continuum emission at $235 \mathrm{GHz}$ is overlaid in white contours with a level step of $0.2 \mathrm{Jy} \mathrm{beam}^{-1}$ (Paper I).

\section{Observations and data reduction}

Acetic acid and ethylene glycol lines toward Orion-KL were observed with 37 antennas on 2014 December 29 and with 39 antennas on 2014 December 30. The two following phase-tracking centers were used to perform the observations: $\alpha_{J 2000}=05^{\mathrm{h}} 35^{\mathrm{m}} 14 \mathrm{~s} 16, \delta_{J 2000}=-05^{\circ} 22^{\prime} 31^{\prime \prime} .504$ and $\alpha_{J 2000}=$ $05^{\mathrm{h}} 35^{\mathrm{m}} 13 \mathrm{~s} 477, \delta_{J 2000}=-05^{\circ} 22^{\prime} 08^{\prime \prime} .50$. The observations lie in the frequency range $215.15 \mathrm{GHz}$ to $252.04 \mathrm{GHz}$ in band 6 and cover about $16 \mathrm{GHz}$ of effective bandwidth with a spectral resolution of about $0.7 \mathrm{~km} \mathrm{~s}^{-1}$. Data reduction and continuum subtraction were performed through the Common Astronomy Software Applications (CASA) software (McMullin et al. 2007). The cleaning of the spectral lines was performed using the GILDAS software ${ }^{1}$. The resulting synthesized beam is typically $1.8^{\prime \prime} \times 1.1^{\prime \prime}\left(\mathrm{PA}\right.$ of $\left.84^{\circ}\right)$. For further details, see Paper I.

\section{Data analysis and results}

\subsection{Acetic acid and ethylene glycol molecular frequencies}

We used the spectroscopic data parameters from Ilyushin et al. (2008) and Ilyushin et al. (2013) for acetic acid, with the following line selection criteria: Einstein spontaneous emission coefficient $A_{i j} \geq 5 \times 10^{-5} \mathrm{~s}^{-1}$ and upper level energy $E_{\text {up }} \leq 400 \mathrm{~K}$. For the partition function we adopted the complete rotationaltorsional-vibrational partition function given by Calcutt, Woods, Carvajal et al. (in prep.).

For the two ethylene glycol conformers we used the spectroscopic data parameters from Christen \& Müller (2003) and Müller \& Christen (2004) that are available from the Cologne Database for Molecular Spectroscopy catalog (CDMS, Müller et al. 2005). More specifically, we searched for transitions up to $E_{\text {up }} \simeq 400 \mathrm{~K}$, and $A_{i j} \geq 1 \times 10^{-4} \mathrm{~s}^{-1}$. The energy difference between the two conformers is about $200 \mathrm{~cm}^{-1}$, the more stable conformer being the $\mathrm{aGg}^{\prime}$-ethylene glycol (Müller \& Christen 2004). Further details about the difference between the $\mathrm{aGg}^{\prime}$ and the $\mathrm{gGg}^{\prime}$ conformer can be found in Brouillet et al. (2015, hereafter BD15).

\footnotetext{
1 http://www.iram.fr/IRAMFR/GILDAS/
}

\subsection{LTE modeling}

Our analysis is based on the assumption that local thermodynamic equilibrium (LTE) is reached. This assumption is reasonable given that LTE modeling of a thousand emissive transitions assigned to simple and complex molecules fits the Herschel/HIFI observations performed toward Orion-KL well (see Crockett et al. 2014). In addition, we assume that all the species emit at the same rotational temperature within the same source size. We used the CLASS extension WEEDS (Maret et al. 2011) to model the acetic acid and ethylene glycol (both $\mathrm{aGg}^{\prime}$ and $\mathrm{gGg}^{\prime}$ conformer) emission, which we assume to be optically thin. We used the values derived for $\mathrm{aGg}^{\prime}\left(\mathrm{CH}_{2} \mathrm{OH}\right)_{2}$ by BD15 as input parameter to initialize our models.

\subsection{Emission map}

The $\mathrm{CH}_{3} \mathrm{COOH}, \mathrm{aGg}^{\prime}\left(\mathrm{CH}_{2} \mathrm{OH}\right)_{2}$ and $\mathrm{gGg}^{\prime}\left(\mathrm{CH}_{2} \mathrm{OH}\right)_{2}$ emission maps integrated over the line profile are shown in Fig. 1. The nominal velocity of Orion-KL is $v_{\mathrm{LSR}}=7.6 \mathrm{~km} \mathrm{~s}^{-1}$. It is important to note that the northwest extension seen in the acetic acid emission map is due to contamination by a U-line (see Appendix C) and is not related to the acetic acid emission. Although we used a restricted $v_{\mathrm{LSR}}$ interval to produce the maps, confusion still dominates the region (Paper I).

A salient result is that the distribution of the emission associated with these molecules is similar within the beam, and the main emission peak is located about $2^{\prime \prime}$ southwest of the hot core, near radio source I and the IR source n. This peak corresponds to the ethylene glycol peak (hereafter EGP) identified by BD15 for the $\mathrm{aGg}^{\prime}\left(\mathrm{CH}_{2} \mathrm{OH}\right)_{2}$ conformer. An outstanding result is that as for the $\mathrm{aGg}^{\prime}\left(\mathrm{CH}_{2} \mathrm{OH}\right)_{2}$ molecule (BD15), the distribution of the emission associated with the acetic acid and the $\mathrm{gGg}^{\prime}$ ethylene glycol conformer differs from that of typical O-bearing species within Orion-KL. Indeed, the emission of the targeted species appears to come from a compact source in the vicinity of the hot core region, while the emission associated with $\mathrm{O}$ bearing molecules, such as methyl formate (e.g., see Favre et al. 2011, and Appendix D), is generally described by an extended V-shape within Orion-KL that links the hot core component to the compact ridge region and extends toward the BN object (e.g., Guélin et al. 2008). 
C. Favre et al.: The complexity of Orion: an ALMA view. II.

Table 1. Best-fit line parameters and derived peak column densities for acetic acid and ethylene glycol toward Orion-KL EGP.

\begin{tabular}{lrrrr|rrrr}
\hline \hline \multirow{2}{*}{ Molecule } & \multicolumn{4}{c}{ Component 1} & \multicolumn{4}{c}{ Component 2 } \\
& $v\left(\mathrm{~km} \mathrm{~s}^{-1}\right)$ & $\Delta v_{1 / 2}\left(\mathrm{~km} \mathrm{~s}^{-1}\right)$ & $T_{\mathrm{rot}}(\mathrm{K})$ & $N\left(10^{15} \mathrm{~cm}^{-2}\right)$ & $v\left(\mathrm{~km} \mathrm{~s}^{-1}\right)$ & $\Delta v_{1 / 2}\left(\mathrm{~km} \mathrm{~s}^{-1}\right)$ & $T_{\mathrm{rot}}(\mathrm{K})$ & $N\left(10^{15} \mathrm{~cm}^{-2}\right)$ \\
\hline $\mathrm{CH}_{3} \mathrm{COOH}$ & 7.9 & 2.5 & 140 & 12 & 5.1 & 2.3 & 140 & 3.3 \\
\hline $\mathrm{aGg}^{\prime}\left(\mathrm{CH}_{2} \mathrm{OH}\right)_{2}$ & 7.8 & 2.1 & 140 & 6.8 & 5.1 & 2.1 & 140 & 1.5 \\
\hline $\mathrm{gGg}^{\prime}\left(\mathrm{CH}_{2} \mathrm{OH}\right)_{2}$ & 7.8 & 2.1 & 140 & 2.7 & 5.1 & 2.1 & 140 & 0.66 \\
\hline
\end{tabular}

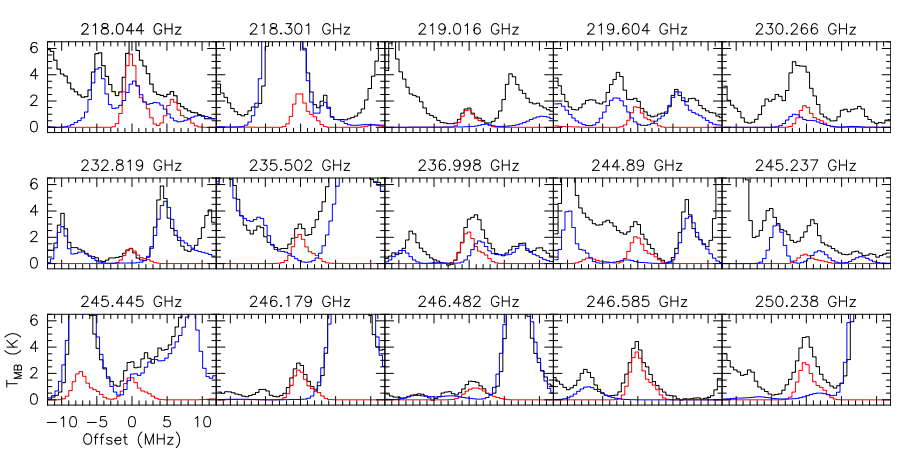

Fig. 2. ALMA observations (black) overlaid with the WEEDS model for acetic acid (red). The sum of the modeled emission from all the other species is overlaid in blue (Paper I).

\subsection{Spectra}

Spectra of a sample of the most intense transitions (i.e., emitting above the $5 \sigma$ level) of acetic acid (15 transitions from $E_{\text {up }}=70 \mathrm{~K}$ up to $318 \mathrm{~K}$, including 5 unblended transitions), $\mathrm{aGg}^{\prime}$ ethylene glycol (50 transitions from $E_{\text {up }}=111 \mathrm{~K}$ up to $266 \mathrm{~K}$, including 19 unblended transitions) and $\mathrm{gGg}^{\prime}$ ethylene glycol ( 22 transitions from $E_{\text {up }}=102 \mathrm{~K}$ up to $216 \mathrm{~K}$, including 5 unblended transitions) toward the EGP region are displayed in Figs. 2, 3, and 4, respectively. In addition, our best by-eye WEEDS fits together with the sum of the modeled emission from all the other species in the region (Paper I) are also overlaid in these figures. Tables A.1, A.2, and A.3 in Appendix A list the spectroscopic line parameters for the displayed acetic acid, $\mathrm{aGg}^{\prime}$-ethylene glycol, and $\mathrm{gGg}^{\prime}$-ethylene glycol transitions, respectively. The bulk of the emission associated with the targeted molecules peaks at about $7.8-7.9 \mathrm{~km} \mathrm{~s}^{-1}$. Nonetheless, all the line profiles display an extended blueshifted wing. Thus, two velocity components, one around $8 \mathrm{~km} \mathrm{~s}^{-1}$ and the other at about $5 \mathrm{~km} \mathrm{~s}^{-1}$, are required to fit the emission. The model parameters that best reproduce the ALMA observations of acetic acid and ethylene glycol (both conformers) in the direction of the EGP region are summarized in Table 1 . In the present analysis we assume an overall uncertainty in the range $30 \%-40 \%$.

\subsection{Column densities and relative abundances}

Table 1 gives the derived $\mathrm{CH}_{3} \mathrm{COOH}, \mathrm{aGg}^{\prime}\left(\mathrm{CH}_{2} \mathrm{OH}\right)_{2}$, and $\mathrm{gGg}^{\prime}\left(\mathrm{CH}_{2} \mathrm{OH}\right)_{2}$ peak column densities assuming a source size of $3^{\prime \prime}$ for each velocity component. We note that our best $\mathrm{aGg}^{\prime}\left(\mathrm{CH}_{2} \mathrm{OH}\right)_{2}$ fit result $\left(v, \Delta_{v}, T_{\text {rot }}\right.$ and $\left.N\right)$ is consistent within the uncertainties $(\sim 30 \%-40 \%)$ with the value reported by BD15.

Table B.1 lists the relative abundance ratios for acetic acid and ethylene glycol derived from our best model results (see Table 1) toward the two velocity components observed in direction of the EGP peak. The derived abundance ratios are equal within the error bars for both velocity components. It is important to note that BD15 reported an upper limit on
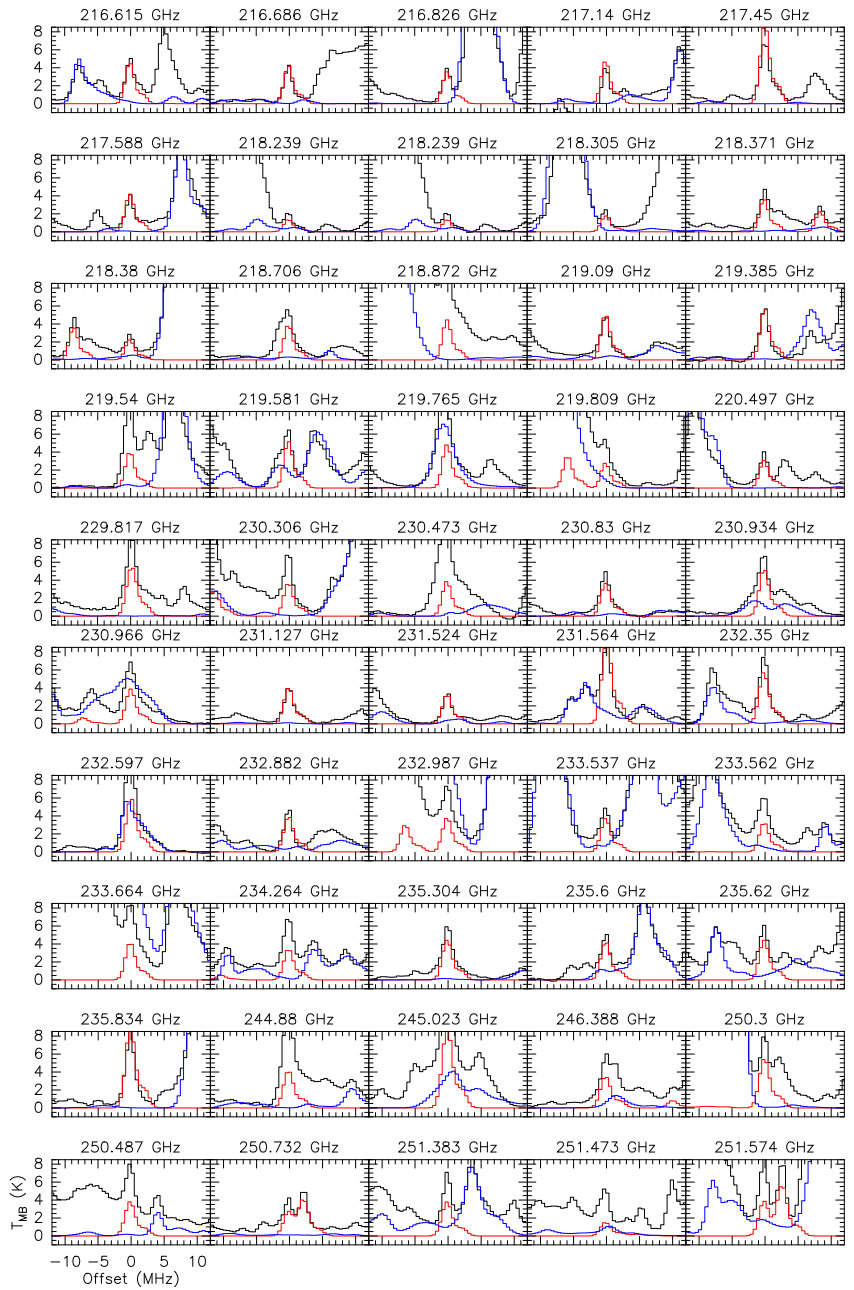

Fig. 3. ALMA observations (black) overlaid with the WEEDS model for $\mathrm{aGg}^{\prime}$ ethylene glycol (red). The sum of the modeled emission from all the other species is overlaid in blue (Paper I).

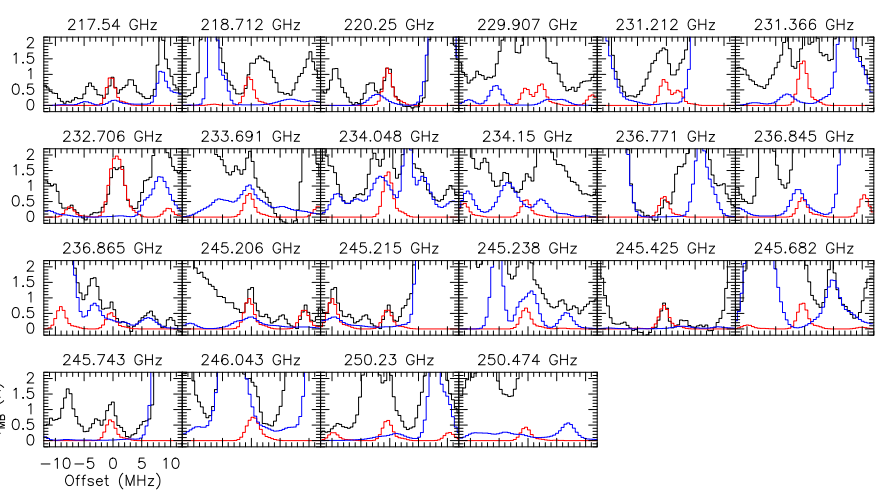

Fig. 4. ALMA observations (black) overlaid with the WEEDS model for $\mathrm{gGg}^{\prime}$ ethylene glycol (red). The sum of the modeled emission from all the other species is overlaid in blue (Paper I). 
the $\mathrm{aGg}^{\prime}\left(\mathrm{CH}_{2} \mathrm{OH}\right)_{2} / \mathrm{gGg}^{\prime}\left(\mathrm{CH}_{2} \mathrm{OH}\right)_{2}$ ratio of 5. This discrepancy apparently results from an underestimate of the limit on the $\mathrm{gGg}^{\prime}\left(\mathrm{CH}_{2} \mathrm{OH}\right)_{2}$ column density by BD15.

\section{Discussion}

In Fig. 5 we show the relative abundance ratios, $\mathrm{CH}_{3} \mathrm{COOH}: \mathrm{aGg}^{\prime}\left(\mathrm{CH}_{2} \mathrm{OH}\right)_{2}: \mathrm{gGg}^{\prime}\left(\mathrm{CH}_{2} \mathrm{OH}\right)_{2}$, derived in this study along with those derived toward the low-mass protostar IRAS $16293-2422$ by Jørgensen et al. (2016). It is immediately apparent that the $\mathrm{CH}_{3} \mathrm{COOH}:\left(\mathrm{CH}_{2} \mathrm{OH}\right)_{2}$ ratios measured in the direction of Orion-KL are higher than those of the low-mass protostar IRAS $16293-2422$ by over an order of magnitude. We also note that the $\mathrm{aGg}^{\prime}\left(\mathrm{CH}_{2} \mathrm{OH}\right)_{2}: \mathrm{gGg}^{\prime}\left(\mathrm{CH}_{2} \mathrm{OH}\right)_{2}$ ratio seems to be, within the error bars, the same for both regions. The fact that Jørgensen et al. (2016) assumed different rotational temperatures for the two conformers to estimate this ratio might explain the slight difference. Lykke et al. (2015) have shown that the source luminosities are likely correlated with relative abundances of complex organic molecules. These findings lead to the question whether and how the physical conditions in these regions, in particular Orion-KL, affect the production and the possible release to the gas-phase of these species.

Both $\mathrm{CH}_{3} \mathrm{COOH}$ and $\left(\mathrm{CH}_{2} \mathrm{OH}\right)_{2}$ are believed to mainly be formed on the icy surface of grains, although gas-phase formation routes cannot be ruled out (see, e.g., Laas et al. 2011; Rivilla et al. 2017). Interestingly enough, Garrod et al. (2008) have shown that ethylene glycol in grain mantles is produced more efficiently than acetic acid by at least one order of magnitude. This naturally explains the observation that the abundance ratio $\mathrm{CH}_{3} \mathrm{COOH} /\left(\mathrm{CH}_{2} \mathrm{OH}\right)_{2}$ is lower in low-mass star-forming regions. However, regarding Orion-KL, an additional mechanism is required to explain the overabundance of $\mathrm{CH}_{3} \mathrm{COOH}$. It is noteworthy that Wright \& Plambeck (2017) have recently proposed that a bullet of matter ejected during the explosive event that occurred $\sim 500-700$ yr ago (Nissen et al. 2012) has impacted the EGP region. More specifically, using high angular resolution ALMA observations, Wright \& Plambeck (2017) have reported a molecular ring in $\mathrm{HC}_{3} \mathrm{~N}, \mathrm{HCN}$, and $\mathrm{SO}_{2}$ that is not associated with continuum emission. In this context, it is important to note that the distribution of acetic acid and ethylene glycol is cospatial with this ring (Fig. E.1). In addition, both acetic acid and ethylene glycol line profiles present a blueshifted emission wing (i.e., the $5 \mathrm{~km} \mathrm{~s}^{-1}$ velocity component), this specific asymmetric line profile being also observed for other molecules in this region (e.g., methanol and formic acid, Paper I). These findings strongly suggest that this region is peculiar and is different from other star-forming regions. The impact that took place here has led to the release of icy COMs in the gas phase, generating the observed gas motions together with a rich molecular composition that may reflect gas-phase chemistry in an induced shock or post-shock stage.

Acknowledgements. CF acknowledges support from the Italian Ministry of Education, Universities and Research, project SIR (RBSI14ZRHR). The authors thank Hannah Calcutt for providing the acetic acid partition function. We also thank Melvyn Wright and Rick Plambeck for their $\mathrm{HC}_{3} \mathrm{~N}$ emission map. This work was carried out in part at the Jet Propulsion Laboratory, which is operated for NASA by the California Institute of Technology. MC acknowledges financial funding from the project FIS2014-53448-C2-2-P (MINECO, Spain), and CMST COST Action CM1405 MOLIM. CF and MC acknowledge support from CMST COST Action CM1401 Our Astro-Chemical History. LP thanks Arnaud Belloche and H.S.P. Müller for their help with molecular spectroscopy data. CF thanks Claudio Codella for an enlightening discussion on shocks. Finally, $\mathrm{CF}$ thanks Vianney Taquet and Franck Hersant for a fruitful discussion about the binding energies and acetic acid formation routes. This paper makes use of the

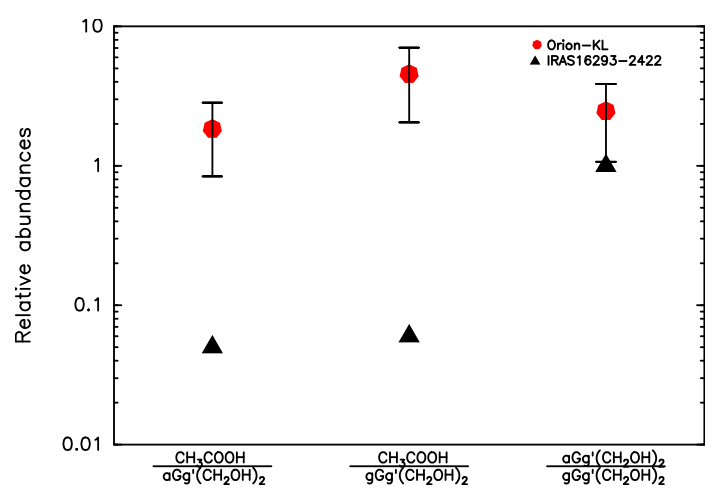

Fig. 5. Acetic acid and ethylene glycol abundance ratios toward OrionKL (red circles, this study) and IRAS 16293-2422 (black triangles, Jørgensen et al. 2016). The ratios for Orion-KL are obtained from the sum of the velocity components given in Table 1 .

following ALMA data: ADS/JAO.ALMA\#2013.1.00533.S. ALMA is a partnership of ESO (representing its member states), NSF (USA) and NINS (Japan), together with NRC (Canada), NSC and ASIAA (Taiwan), and KASI (Republic of Korea), in cooperation with the Republic of Chile. The Joint ALMA Observatory is operated by ESO, AUI/NRAO and NAOJ.

\section{References}

Bergin, E. A., Phillips, T. G., Comito, C., et al. 2010, A\&A, 521, L20 Brouillet, N., Despois, D., Lu, X.-H., et al. 2015, A\&A, 576, A129

Christen, D., \& Müller, H. S. P. 2003, Physical Chemistry Chemical Physics (Incorporating Faraday Transactions), 5, 3600

Crockett, N. R., Bergin, E. A., Neill, J. L., et al. 2014, ApJ, 787, 112

Favre, C., Bergin, E. A., Neill, J. L., et al. 2015, ApJ, 808, 155

Favre, C., Despois, D., Brouillet, N., et al. 2011, A\&A, 532, A32

Fuente, A., Cernicharo, J., Caselli, P., et al. 2014, A\&A, 568, A65

Garrod, R. T., Weaver, S. L. W., \& Herbst, E. 2008, ApJ, 682, 283

Goddi, C., Humphreys, E. M. L., Greenhill, L. J., Chandler, C. J., \& Matthews, L. D. 2011, ApJ, 728, 15

Guélin, M., Brouillet, N., Cernicharo, J., Combes, F., \& Wooten, A. 2008, Ap\&SS, 313, 45

Herbst, E., \& van Dishoeck, E. F. 2009, ARA\&A, 47, 427

Ilyushin, V., Kleiner, I., \& Lovas, F. J. 2008, J. Phys. Chem. Ref. Data, 37, 97

Ilyushin, V. V., Endres, C. P., Lewen, F., Schlemmer, S., \& Drouin, B. J. 2013, J. Mol. Spectr., 290, 31

Jørgensen, J. K., van der Wiel, M. H. D., Coutens, A., et al. 2016, A\&A, 595, A117

Kounkel, M., Hartmann, L., Loinard, L., et al. 2017, ApJ, 834, 142

Laas, J. C., Garrod, R. T., Herbst, E., \& Widicus Weaver, S. L. 2011, ApJ, 728, 71

Lykke, J. M., Favre, C., Bergin, E. A., \& Jørgensen, J. K. 2015, A\&A, 582, A64 Maret, S., Hily-Blant, P., Pety, J., Bardeau, S., \& Reynier, E. 2011, A\&A, 526, A47

McMullin, J. P., Waters, B., Schiebel, D., Young, W., \& Golap, K. 2007, in Astronomical Data Analysis Software and Systems XVI, eds. R. A. Shaw, F. Hill, \& D. J. Bell, ASP Conf. Ser., 376, 127

Müller, H. S. P., \& Christen, D. 2004, J. Mol. Spectr., 228, 298

Müller, H. S. P., Schlöder, F., Stutzki, J., \& Winnewisser, G. 2005, J. Mol. Struct., 742,215

Nissen, H. D., Cunningham, N. J., Gustafsson, M., et al. 2012, A\&A, 540, A119 Pagani, L., Favre, C., Goldsmith, P. F., et al. 2017, A\&A, 604, A32

Remijan, A., Snyder, L. E., Friedel, D. N., Liu, S., \& Shah, R. Y. 2003, ApJ, 590, 314

Rivilla, V. M., Beltrán, M. T., Cesaroni, R., et al. 2017, A\&A, 598, A59

Shiao, Y., Looney, L. W., Remijan, A. J., Snyder, L. E., \& Friedel, D. N. 2010, ApJ, 716, 286

Tercero, B., Cernicharo, J., Pardo, J. R., \& Goicoechea, J. R. 2010, A\&A, 517, A96

Tercero, B., Vincent, L., Cernicharo, J., Viti, S., \& Marcelino, N. 2011, A\&A, 528, A26

Wright, M. C. H., \& Plambeck, R. L. 2017, ApJ, 843, 83

Zapata, L. A., Schmid-Burgk, J., \& Menten, K. M. 2011, A\&A, 529, A24 
C. Favre et al.: The complexity of Orion: an ALMA view. II.

\section{Appendix A: Spectroscopic line parameters}

Tables A.1-A.3 list the spectroscopic line parameters for the acetic acid, aGg'-ethylene glycol, and $\mathrm{gGg}^{\prime}-$ ethylene glycol lines that are displayed in Figs. 2-4, respectively.

Table A.1. Spectroscopic data of the acetic acid lines displayed in Fig. 2

\begin{tabular}{|c|c|c|c|c|c|c|}
\hline \multirow{2}{*}{$\begin{array}{c}\text { Frequency } \\
(\mathrm{MHz})\end{array}$} & \multirow[t]{2}{*}{ Symmetry } & \multicolumn{2}{|c|}{ Quantum number } & \multirow{2}{*}{$\begin{array}{c}A_{\mathrm{u}, 1} \\
\left(\mathrm{~s}^{-1}\right)\end{array}$} & \multirow[t]{2}{*}{$g_{\text {up }}$} & \multirow{2}{*}{$\begin{array}{l}E_{\text {up }} \\
(\mathrm{K})\end{array}$} \\
\hline & & $J_{K_{a}, K_{c}}, v_{t}($ up $)$ & $J_{K_{a}, K_{c}}, v_{t}($ low $)$ & & & \\
\hline 218044.2146 & A & $20_{(0,20)}, v_{t}=0$ & $19_{(1,19)}, v_{t}=0$ & $2.25 \mathrm{e}-05$ & 82 & 112.2 \\
\hline 218044.2146 & A & $20_{(1,20)}, v_{t}=0$ & $19_{(0,19)}, v_{t}=0$ & $2.25 \mathrm{e}-05$ & 82 & 112.2 \\
\hline 218044.2146 & A & $20_{(0,20)}, v_{t}=0$ & $19_{(0,19)}, v_{t}=0$ & $6.06 \mathrm{e}-05$ & 82 & 112.2 \\
\hline 218044.2146 & A & $20_{(1,20)}, v_{t}=0$ & $19_{(1,19)}, v_{t}=0$ & $6.06 \mathrm{e}-05$ & 82 & 112.2 \\
\hline 218301.0685 & $\mathrm{E}$ & $20_{(0,20)}, v_{t}=1$ & $19_{(0,19)}, v_{t}=1$ & $2.44 \mathrm{e}-08$ & 82 & 217.4 \\
\hline 218301.0685 & $\mathrm{E}$ & $20_{(1,20)}, v_{t}=1$ & $19_{(1,19)}, v_{t}=1$ & $2.44 \mathrm{e}-08$ & 82 & 217.4 \\
\hline 218301.0685 & $\mathrm{E}$ & $20_{(0,20)}, v_{t}=1$ & $19_{(1,19)}, v_{t}=1$ & $8.31 \mathrm{e}-05$ & 82 & 217.4 \\
\hline 218301.0685 & $\mathrm{E}$ & $20_{(1,20)}, v_{t}=1$ & $19_{(0,19)}, v_{t}=1$ & $8.31 \mathrm{e}-05$ & 82 & 217.4 \\
\hline 219016.0364 & $\mathrm{E}$ & $20_{(0,20)}, v_{t}=2$ & $19_{(1,19)}, v_{t}=2$ & $6.41 \mathrm{e}-05$ & 82 & 309.0 \\
\hline 219016.0365 & $\mathrm{E}$ & $20_{(0,20)}, v_{t}=2$ & $19_{(0,19)}, v_{t}=2$ & $1.77 \mathrm{e}-05$ & 82 & 309.0 \\
\hline 219016.0385 & $\mathrm{E}$ & $20_{(1,20)}, v_{t}=2$ & $19_{(1,19)}, v_{t}=2$ & $1.77 \mathrm{e}-05$ & 82 & 309.0 \\
\hline 219016.0386 & $\mathrm{E}$ & $20_{(1,20)}, v_{t}=2$ & $19_{(0,19)}, v_{t}=2$ & $6.41 \mathrm{e}-05$ & 82 & 309.0 \\
\hline 219603.9437 & $\mathrm{~A}$ & $20_{(0,20)}, v_{t}=2$ & $19_{(1,19)}, v_{t}=2$ & $6.51 \mathrm{e}-06$ & 82 & 289.1 \\
\hline 219603.9437 & A & $20_{(1,20)}, v_{t}=2$ & $19_{(1,19)}, v_{t}=2$ & $7.77 \mathrm{e}-05$ & 82 & 289.1 \\
\hline 219603.9446 & $\mathrm{~A}$ & $20_{(1,20)}, v_{t}=2$ & $19_{(0,19)}, v_{t}=2$ & $6.51 \mathrm{e}-06$ & 82 & 289.1 \\
\hline 219603.9446 & $\mathrm{~A}$ & $20_{(0,20)}, v_{t}=2$ & $19_{(0,19)}, v_{t}=2$ & $7.77 \mathrm{e}-05$ & 82 & 289.1 \\
\hline 230266.0061 & A & $21_{(0,21)}, v_{t}=2$ & $20_{(1,20)}, v_{t}=2$ & $2.71 \mathrm{e}-05$ & 86 & 300.2 \\
\hline 230266.0061 & A & $21_{(1,21)}, v_{t}=2$ & $20_{(0,20)}, v_{t}=2$ & $2.71 \mathrm{e}-05$ & 86 & 300.2 \\
\hline 230266.0061 & A & $21_{(0,21)}, v_{t}=2$ & $20_{(0,20)}, v_{t}=2$ & $7.02 \mathrm{e}-05$ & 86 & 300.2 \\
\hline 230266.0061 & A & $21_{(1,21)}, v_{t}=2$ & $20_{(1,20)}, v_{t}=2$ & $7.02 \mathrm{e}-05$ & 86 & 300.2 \\
\hline 232818.7007 & $\mathrm{E}$ & $19_{(2,17)}, v_{t}=2$ & $18_{(3,16)}, v_{t}=2$ & $7.31 \mathrm{e}-05$ & 78 & 317.7 \\
\hline 232818.7077 & $\mathrm{E}$ & $19_{(3,17)}, v_{t}=2$ & $18_{(3,16)}, v_{t}=2$ & $1.06 \mathrm{e}-05$ & 78 & 317.7 \\
\hline 232818.7318 & $\mathrm{E}$ & $19_{(2,17)}, v_{t}=2$ & $18_{(2,16)}, v_{t}=2$ & $1.06 \mathrm{e}-05$ & 78 & 317.7 \\
\hline 232818.7388 & $\mathrm{E}$ & $19_{(3,17)}, v_{t}=2$ & $18_{(2,16)}, v_{t}=2$ & $7.31 \mathrm{e}-05$ & 78 & 317.7 \\
\hline 235501.6832 & $\mathrm{~A}$ & $20_{(2,18)}, v_{t}=1$ & $19_{(3,17)}, v_{t}=1$ & $3.21 \mathrm{e}-05$ & 82 & 241.5 \\
\hline 235501.6832 & $\mathrm{~A}$ & $20_{(3,18)}, v_{t}=1$ & $19_{(2,17)}, v_{t}=1$ & $3.21 \mathrm{e}-05$ & 82 & 241.5 \\
\hline 235501.6832 & A & $20_{(2,18)}, v_{t}=1$ & $19_{(2,17)}, v_{t}=1$ & $6.14 \mathrm{e}-05$ & 82 & 241.5 \\
\hline 235501.6832 & A & $20_{(3,18)}, v_{t}=1$ & $19_{(3,17)}, v_{t}=1$ & $6.14 \mathrm{e}-05$ & 82 & 241.5 \\
\hline 236998.1508 & A & $21_{(1,20)}, v_{t}=1$ & $20_{(1,19)}, v_{t}=1$ & $1.01 \mathrm{e}-04$ & 86 & 245.0 \\
\hline 236998.1508 & A & $21_{(2,20)}, v_{t}=1$ & $20_{(2,19)}, v_{t}=1$ & $1.01 \mathrm{e}-04$ & 86 & 245.0 \\
\hline 236998.1508 & A & $21_{(1,20)}, v_{t}=1$ & $20_{(2,19)}, v_{t}=1$ & $1.42 \mathrm{e}-07$ & 86 & 245.0 \\
\hline 236998.1508 & A & $21_{(2,20)}, v_{t}=1$ & $20_{(1,19)}, v_{t}=1$ & $1.42 \mathrm{e}-07$ & 86 & 245.0 \\
\hline 244889.6209 & $\mathrm{~A}$ & $20_{(3,17)}, v_{t}=1$ & $19_{(3,16)}, v_{t}=1$ & $2.42 \mathrm{e}-05$ & 82 & 249.1 \\
\hline 244889.6209 & A & $20_{(4,17)}, v_{t}=1$ & $19_{(4,16)}, v_{t}=1$ & $2.42 \mathrm{e}-05$ & 82 & 249.1 \\
\hline 244889.6209 & A & $20_{(3,17)}, v_{t}=1$ & $19_{(4,16)}, v_{t}=1$ & $7.48 \mathrm{e}-05$ & 82 & 249.1 \\
\hline 244889.6209 & A & $20_{(4,17)}, v_{t}=1$ & $19_{(3,16)}, v_{t}=1$ & $7.48 \mathrm{e}-05$ & 82 & 249.1 \\
\hline 245237.0813 & A & $12_{(11,1)}, v_{t}=1$ & $11_{(10,2)}, v_{t}=1$ & $7.14 \mathrm{e}-05$ & 50 & 187.2 \\
\hline 245444.9402 & $\mathrm{E}$ & $11_{(11,1)}, v_{t}=0$ & $10_{(10,1)}, v_{t}=0$ & $8.23 \mathrm{e}-05$ & 46 & 70.1 \\
\hline 246179.2041 & A & $21_{(2,19)}, v_{t}=1$ & $20_{(3,18)}, v_{t}=1$ & $3.88 \mathrm{e}-05$ & 86 & 253.3 \\
\hline 246179.2041 & A & $21_{(3,19)}, v_{t}=1$ & $20_{(2,18)}, v_{t}=1$ & $3.88 \mathrm{e}-05$ & 86 & 253.3 \\
\hline 246179.2041 & A & $21_{(2,19)}, v_{t}=1$ & $20_{(2,18)}, v_{t}=1$ & $6.89 \mathrm{e}-05$ & 86 & 253.3 \\
\hline 246179.2041 & A & $21_{(3,19)}, v_{t}=1$ & $20_{(3,18)}, v_{t}=1$ & $6.89 \mathrm{e}-05$ & 86 & 253.3 \\
\hline 246481.9960 & A & $19_{(3,16)}, v_{t}=2$ & $18_{(4,15)}, v_{t}=2$ & $6.01 \mathrm{e}-05$ & 78 & 309.9 \\
\hline 246584.8477 & $\mathrm{E}$ & $18_{(5,13)}, v_{t}=0$ & $17_{(6,12)}, v_{t}=0$ & $6.11 \mathrm{e}-05$ & 74 & 129.1 \\
\hline 246584.8511 & $\mathrm{E}$ & $18_{(6,13)}, v_{t}=0$ & $17_{(6,12)}, v_{t}=0$ & $2.23 \mathrm{e}-05$ & 74 & 129.1 \\
\hline 246584.8724 & $\mathrm{E}$ & $18_{(5,13)}, v_{t}=0$ & $17_{(5,12)}, v_{t}=0$ & $2.23 \mathrm{e}-05$ & 74 & 129.1 \\
\hline 246584.8759 & $\mathrm{E}$ & $18_{(6,13)}, v_{t}=0$ & $17_{(5,12)}, v_{t}=0$ & $6.11 \mathrm{e}-05$ & 74 & 129.1 \\
\hline 250237.9675 & $\mathrm{E}$ & $23_{(0,23)}, v_{t}=1$ & $22_{(0,22)}, v_{t}=1$ & $1.11 \mathrm{e}-04$ & 94 & 251.9 \\
\hline 250237.9675 & $\mathrm{E}$ & $23_{(1,23)}, v_{t}=1$ & $22_{(1,22)}, v_{t}=1$ & $1.11 \mathrm{e}-04$ & 94 & 251.9 \\
\hline 250237.9675 & $\mathrm{E}$ & $23_{(0,23)}, v_{t}=1$ & $22_{(1,22)}, v_{t}=1$ & $1.54 \mathrm{e}-05$ & 94 & 251.9 \\
\hline 250237.9675 & $\mathrm{E}$ & $23_{(1,23)}, v_{t}=1$ & $22_{(0,22)}, v_{t}=1$ & $1.54 \mathrm{e}-05$ & 94 & 251.9 \\
\hline
\end{tabular}


Table A.2. Spectroscopic data of the aGg' ethylene glycol lines displayed in Fig. 3.

\begin{tabular}{|c|c|c|c|c|c|}
\hline \multirow{2}{*}{$\begin{array}{c}\text { Frequency } \\
(\mathrm{MHz})\end{array}$} & \multicolumn{2}{|c|}{ Quantum number ${ }^{a}$} & \multirow{2}{*}{$\begin{array}{c}A_{\mathrm{u}, 1} \\
\mathrm{~s}^{-1}\end{array}$} & \multirow[t]{2}{*}{$g_{\text {up }}$} & \multirow{2}{*}{$\begin{array}{l}E_{\mathrm{up}} \\
(\mathrm{K})\end{array}$} \\
\hline & $J_{K_{a}, K_{c}}, v($ up $)$ & $J_{K_{a}, K_{c}}, v($ low $)$ & & & \\
\hline 216614.952 & $20_{(3,17)}, v=1$ & $19_{(3,16)}, v=0$ & $2.222 \mathrm{E}-04$ & 369 & 110.8 \\
\hline 216685.815 & $21_{(3,19)}, v=1$ & $20_{(3,18)}, v=0$ & $2.030 \mathrm{E}-04$ & 387 & 117.3 \\
\hline 216826.112 & $20_{(5,15)}, v=1$ & $19_{(5,14)}, v=0$ & $1.792 \mathrm{E}-04$ & 369 & 116.8 \\
\hline 217139.723 & $21_{(4,17)}, v=0$ & $20_{(4,16)}, v=1$ & $2.423 \mathrm{E}-04$ & 387 & 123.9 \\
\hline 217449.995 & $24_{(1,24)}, v=0$ & $23_{(1,23)}, v=1$ & $2.520 \mathrm{E}-04$ & 441 & 136.4 \\
\hline 217450.270 & $24_{(0,24)}, v=0$ & $23_{(0,23)}, v=1$ & $2.520 \mathrm{E}-04$ & 343 & 136.4 \\
\hline 217587.548 & $21_{(2,19)}, v=1$ & $20_{(2,18)}, v=0$ & 2.654E-04 & 301 & 117.2 \\
\hline 218238.988 & $22_{(17,5)}, v=0$ & $21_{(17,4)}, v=1$ & $1.018 \mathrm{E}-04$ & 315 & 266.2 \\
\hline 218238.988 & $22_{(17,6)}, v=0$ & $21_{(17,5)}, v=1$ & $1.018 \mathrm{E}-04$ & 405 & 266.2 \\
\hline 218304.671 & $22_{(16,6)}, v=0$ & $21_{(16,5)}, v=1$ & $1.192 \mathrm{E}-04$ & 315 & 250.0 \\
\hline 218304.671 & $22_{(16,7)}, v=0$ & $21_{(16,6)}, v=1$ & $1.192 \mathrm{E}-04$ & 405 & 250.0 \\
\hline 218371.495 & $22_{(4,19)}, v=0$ & $21_{(4,18)}, v=1$ & $1.881 \mathrm{E}-04$ & 405 & 132.6 \\
\hline 218379.983 & $22_{(15,7)}, v=0$ & $21_{(15,6)}, v=1$ & $1.355 \mathrm{E}-04$ & 315 & 234.8 \\
\hline 218379.983 & $22_{(15,8)}, v=0$ & $21_{(15,7)}, v=1$ & $1.355 \mathrm{E}-04$ & 405 & 234.8 \\
\hline 218705.810 & $22_{(12,10)}, v=0$ & $21_{(12,9)}, v=1$ & $1.786 \mathrm{E}-04$ & 315 & 195.1 \\
\hline 218705.810 & $22_{(12,11)}, v=0$ & $21_{(12,10)}, v=1$ & $1.786 \mathrm{E}-04$ & 405 & 195.1 \\
\hline 218872.112 & $22_{(11,12)}, v=0$ & $21_{(11,11)}, v=1$ & $1.911 \mathrm{E}-04$ & 405 & 183.8 \\
\hline 218872.112 & $22_{(11,11)}, v=0$ & $21_{(11,10)}, v=1$ & 1.911E-04 & 315 & 183.8 \\
\hline 219089.720 & $22_{(10,13)}, v=0$ & $21_{(10,12)}, v=1$ & 2.027E-04 & 405 & 173.5 \\
\hline 219089.728 & $22_{(10,12)}, v=0$ & $21_{(10,11)}, v=1$ & 2.027E-04 & 315 & 173.5 \\
\hline 219385.178 & $22_{(9,14)}, v=0$ & $21_{(9,13)}, v=1$ & $2.136 \mathrm{E}-04$ & 405 & 164.3 \\
\hline 219385.426 & $22_{(9,13)}, v=0$ & $21_{(9,12)}, v=1$ & $2.136 \mathrm{E}-04$ & 315 & 164.3 \\
\hline 219540.443 & $22_{(2,21)}, v=1$ & $21_{(2,20)}, v=0$ & $2.539 \mathrm{E}-04$ & 315 & 122.1 \\
\hline 219580.672 & $22_{(1,21)}, v=1$ & $21_{(1,20)}, v=0$ & $2.568 \mathrm{E}-04$ & 405 & 122.0 \\
\hline 219764.926 & $20_{(4,16)}, v=1$ & $19_{(4,15)}, v=0$ & $2.454 \mathrm{E}-04$ & 369 & 113.5 \\
\hline 219809.406 & $22_{(8,14)}, v=0$ & $21_{(8,13)}, v=1$ & $2.238 \mathrm{E}-04$ & 315 & 156.0 \\
\hline 220496.592 & $22_{(7,15)}, v=0$ & $21_{(7,14)}, v=1$ & 2.339E-04 & 315 & 148.8 \\
\hline 229816.573 & $23_{(9,15)}, v=0$ & $22_{(9,14)}, v=1$ & $2.499 \mathrm{E}-04$ & 329 & 175.6 \\
\hline 229817.111 & $23_{(9,14)}, v=0$ & $22_{(9,13)}, v=1$ & 2.499E-04 & 423 & 175.6 \\
\hline 230305.630 & $23_{(8,15)}, v=0$ & $22_{(8,14)}, v=1$ & $2.610 \mathrm{E}-04$ & 423 & 167.4 \\
\hline 230472.528 & $21_{(4,17)}, v=1$ & $20_{(4,16)}, v=0$ & $2.836 \mathrm{E}-04$ & 301 & 124.2 \\
\hline 230830.319 & $24_{(2,22)}, v=0$ & $23_{(2,21)}, v=1$ & 2.822E-04 & 343 & 149.8 \\
\hline 230933.676 & $23_{(3,20)}, v=0$ & $22_{(3,19)}, v=1$ & $3.166 \mathrm{E}-04$ & 423 & 143.3 \\
\hline 230965.547 & $23_{(7,17)}, v=0$ & $22_{(7,16)}, v=1$ & $2.715 \mathrm{E}-04$ & 329 & 160.2 \\
\hline 231127.401 & $23_{(7,16)}, v=0$ & $22_{(7,15)}, v=1$ & 2.722E-04 & 423 & 160.2 \\
\hline 231524.033 & $23_{(6,18)}, v=0$ & $22_{(6,17)}, v=1$ & 2.714E-04 & 329 & 154.1 \\
\hline 231564.005 & $24_{(1,24)}, v=1$ & $23_{(1,23)}, v=0$ & 3.043E-04 & 343 & 136.8 \\
\hline 231564.320 & $24_{(0,24)}, v=1$ & $23_{(0,23)}, v=0$ & $3.043 \mathrm{E}-04$ & 441 & 136.8 \\
\hline 232350.059 & $22_{(10,13)}, v=1$ & $21_{(10,12)}, v=0$ & $2.420 \mathrm{E}-04$ & 315 & 173.8 \\
\hline 232350.068 & $22_{(10,12)}, v=1$ & $21_{(10,11)}, v=0$ & $2.420 \mathrm{E}-04$ & 405 & 173.8 \\
\hline 232597.215 & $22_{(9,14)}, v=1$ & $21_{(9,13)}, v=0$ & 2.549E-04 & 315 & 164.6 \\
\hline 232597.490 & $22_{(9,13)}, v=1$ & $21_{(9,12)}, v=0$ & $2.548 \mathrm{E}-04$ & 405 & 164.6 \\
\hline 232881.533 & $23_{(6,17)}, v=0$ & $22_{(6,16)}, v=1$ & 2.607E-04 & 423 & 154.3 \\
\hline 232987.353 & $22_{(8,14)}, v=1$ & $21_{(8,13)}, v=0$ & $2.669 \mathrm{E}-04$ & 405 & 156.3 \\
\hline 233536.696 & $22_{(5,18)}, v=1$ & $21_{(5,17)}, v=0$ & $2.930 \mathrm{E}-04$ & 315 & 137.7 \\
\hline 233561.785 & $22_{(7,16)}, v=1$ & $21_{(7,15)}, v=0$ & $2.785 \mathrm{E}-04$ & 315 & 149.1 \\
\hline 233664.319 & $22_{(7,15)}, v=1$ & $21_{(7,14)}, v=0$ & $2.788 \mathrm{E}-04$ & 405 & 149.1 \\
\hline 234264.446 & $22_{(6,17)}, v=1$ & $21_{(6,16)}, v=0$ & $2.839 \mathrm{E}-04$ & 315 & 143.0 \\
\hline 235304.050 & $22_{(6,16)}, v=1$ & $21_{(6,15)}, v=0$ & 2.897E-04 & 405 & 143.1 \\
\hline 235600.179 & $23_{(2,21)}, v=1$ & $22_{(2,20)}, v=0$ & $3.276 \mathrm{E}-04$ & 329 & 138.7 \\
\hline 235620.372 & $24_{(4,21)}, v=0$ & $23_{(4,20)}, v=1$ & 2.881E-04 & 441 & 155.4 \\
\hline 235834.240 & $26_{(1,26)}, v=0$ & $25_{(1,25)}, v=1$ & $3.222 \mathrm{E}-04$ & 477 & 159.3 \\
\hline 235834.327 & $26_{(0,26)}, v=0$ & $25_{(0,25)}, v=1$ & $3.221 \mathrm{E}-04$ & 371 & 159.3 \\
\hline
\end{tabular}

Notes. ${ }^{(a)}$ Tunnelling is observed between two equivalent equilibrium configurations and splits each rotational level into two distinct states designated as $v=0$ and $v=1$ (BD15). 
C. Favre et al.: The complexity of Orion: an ALMA view. II.

Table A.2. continued.

\begin{tabular}{|c|c|c|c|c|c|}
\hline \multirow{2}{*}{$\begin{array}{c}\text { Frequency } \\
(\mathrm{MHz})\end{array}$} & \multicolumn{2}{|c|}{ Quantum number ${ }^{a}$} & \multirow{2}{*}{$\begin{array}{c}A_{\mathrm{u}, 1} \\
\mathrm{~s}^{-1}\end{array}$} & \multirow[t]{2}{*}{$g_{\text {up }}$} & \multirow{2}{*}{$\begin{array}{l}E_{\text {up }} \\
(\mathrm{K})\end{array}$} \\
\hline & $J_{K_{a}, K_{c}}, v($ up $)$ & $J_{K_{a}, K_{c}}, v($ low $)$ & & & \\
\hline 244879.919 & $23_{(6,18)}, v=1$ & $22_{(6,17)}, v=0$ & $3.028 \mathrm{E}-04$ & 423 & 154.4 \\
\hline 245022.738 & $27_{(1,27)}, v=0$ & $26_{(1,26)}, v=1$ & $3.616 \mathrm{E}-04$ & 385 & 171.4 \\
\hline 245022.787 & $27_{(0,27)}, v=0$ & $26_{(0,26)}, v=1$ & 3.617E-04 & 495 & 171.4 \\
\hline 246387.881 & $23_{(6,17)}, v=1$ & $22_{(6,16)}, v=0$ & $3.280 \mathrm{E}-04$ & 329 & 154.6 \\
\hline 250300.410 & $25_{(10,16)}, v=0$ & $24_{(10,15)}, v=1$ & $3.208 \mathrm{E}-04$ & 357 & 209.0 \\
\hline 250300.508 & $25_{(10,15)}, v=0$ & $24_{(10,14)}, v=1$ & $3.209 \mathrm{E}-04$ & 459 & 209.0 \\
\hline 250487.421 & $23_{(5,18)}, v=1$ & $22_{(5,17)}, v=0$ & $3.606 \mathrm{E}-04$ & 329 & 150.3 \\
\hline 250731.885 & $25_{(9,17)}, v=0$ & $24_{(9,16)}, v=1$ & $3.341 \mathrm{E}-04$ & 357 & 199.8 \\
\hline 250734.147 & $25_{(9,16)}, v=0$ & $24_{(9,15)}, v=1$ & $3.341 \mathrm{E}-04$ & 459 & 199.8 \\
\hline 251382.563 & $25_{(8,17)}, v=0$ & $24_{(8,16)}, v=1$ & $3.471 \mathrm{E}-04$ & 459 & 191.6 \\
\hline 251473.045 & $25_{(6,20)}, v=0$ & $24_{(6,19)}, v=1$ & $1.607 \mathrm{E}-04$ & 357 & 178.4 \\
\hline 251574.351 & $27_{(2,26)}, v=0$ & $26_{(2,25)}, v=1$ & 3.873E-04 & 385 & 179.3 \\
\hline 251577.144 & $27_{(1,26)}, v=0$ & $26_{(1,25)}, v=1$ & $3.870 \mathrm{E}-04$ & 495 & 179.3 \\
\hline
\end{tabular}

Table A.3. Spectroscopic data of the $\mathrm{gGg}^{\prime}$ ethylene glycol lines displayed in Fig. 4.

\begin{tabular}{|c|c|c|c|c|c|}
\hline \multirow{2}{*}{$\begin{array}{c}\text { frequency } \\
(\mathrm{MHz})\end{array}$} & \multicolumn{2}{|c|}{ Quantum number ${ }^{a}$} & \multirow{2}{*}{$\begin{array}{c}A_{\mathrm{u}, 1} \\
\left(\mathrm{~s}^{-1}\right)\end{array}$} & \multirow[t]{2}{*}{$g_{\text {up }}$} & \multirow{2}{*}{$\begin{array}{l}E_{\mathrm{up}} \\
(\mathrm{K})\end{array}$} \\
\hline & $J_{K_{a}, K_{c}}, v($ up $)$ & $\mathrm{J}_{K_{a}, K_{c}}, v($ low $)$ & & & \\
\hline 217539.718 & $22_{(2,20)}, v=0$ & $21_{(2,19)}, v=1$ & $1.495 \mathrm{E}-04$ & 315 & 126.6 \\
\hline 218712.336 & $22_{(3,20)}, v=1$ & $21_{(3,19)}, v=0$ & $1.512 \mathrm{E}-04$ & 315 & 126.7 \\
\hline 220249.787 & $22_{(2,20)}, v=1$ & $21_{(2,19)}, v=0$ & $1.550 \mathrm{E}-04$ & 405 & 126.7 \\
\hline 229906.833 & $24_{(2,23)}, v=1$ & $23_{(1,22)}, v=1$ & $1.013 \mathrm{E}-04$ & 343 & 142.7 \\
\hline 231212.070 & $24_{(1,23)}, v=1$ & $23_{(1,22)}, v=0$ & $1.210 \mathrm{E}-04$ & 441 & 142.7 \\
\hline 231366.043 & $25_{(1,25)}, v=0$ & $24_{(1,24)}, v=1$ & $1.185 \mathrm{E}-04$ & 357 & 147.0 \\
\hline 231366.176 & $25_{(0,25)}, v=0$ & $24_{(0,24)}, v=1$ & $1.184 \mathrm{E}-04$ & 459 & 147.0 \\
\hline 232706.108 & $25_{(0,25)}, v=1$ & $24_{(1,24)}, v=1$ & 1.199E-04 & 357 & 147.1 \\
\hline 232706.561 & $25_{(1,25)}, v=1$ & $24_{(0,24)}, v=1$ & $1.201 \mathrm{E}-04$ & 459 & 147.1 \\
\hline 233690.540 & $22_{(4,18)}, v=1$ & $21_{(4,17)}, v=0$ & $1.118 \mathrm{E}-04$ & 405 & 134.2 \\
\hline 234047.938 & $25_{(1,25)}, v=1$ & $24_{(1,24)}, v=0$ & $1.225 \mathrm{E}-04$ & 459 & 147.1 \\
\hline 234048.079 & $25_{(0,25)}, v=1$ & $24_{(0,24)}, v=0$ & $1.226 \mathrm{E}-04$ & 357 & 147.1 \\
\hline 234150.007 & $23_{(8,15)}, v=0$ & $22_{(8,14)}, v=1$ & $1.039 \mathrm{E}-04$ & 423 & 166.1 \\
\hline 236771.321 & $23_{(6,17)}, v=0$ & $22_{(6,16)}, v=1$ & $1.139 \mathrm{E}-04$ & 423 & 153.1 \\
\hline 236845.214 & $23_{(7,17)}, v=1$ & $22_{(7,16)}, v=0$ & $1.102 \mathrm{E}-04$ & 423 & 159.0 \\
\hline 236864.590 & $23_{(3,20)}, v=1$ & $22_{(3,19)}, v=0$ & $1.058 \mathrm{E}-04$ & 329 & 142.4 \\
\hline 245205.575 & $25_{(2,23)}, v=0$ & $24_{(3,22)}, v=0$ & $1.714 \mathrm{E}-04$ & 459 & 160.6 \\
\hline 245215.148 & $24_{(7,18)}, v=0$ & $23_{(7,17)}, v=1$ & $1.232 \mathrm{E}-04$ & 441 & 170.8 \\
\hline 245238.282 & $24_{(12,12)}, v=1$ & $23_{(12,11)}, v=0$ & $1.016 \mathrm{E}-04$ & 441 & 216.4 \\
\hline 245238.282 & $24_{(12,13)}, v=1$ & $23_{(12,12)}, v=0$ & $1.016 \mathrm{E}-04$ & 343 & 216.4 \\
\hline 245424.852 & $24_{(11,14)}, v=1$ & $23_{(11,13)}, v=0$ & $1.073 \mathrm{E}-04$ & 343 & 205.3 \\
\hline 245424.853 & $24_{(11,13)}, v=1$ & $23_{(11,12)}, v=0$ & $1.073 \mathrm{E}-04$ & 441 & 205.3 \\
\hline 245681.514 & $24_{(10,15)}, v=1$ & $23_{(10,14)}, v=0$ & $1.126 \mathrm{E}-04$ & 343 & 195.2 \\
\hline 245681.559 & $24_{(10,14)}, v=1$ & $23_{(10,13)}, v=0$ & $1.126 \mathrm{E}-04$ & 441 & 195.2 \\
\hline 245742.900 & $24_{(6,19)}, v=0$ & $23_{(6,18)}, v=1$ & $1.280 \mathrm{E}-04$ & 441 & 164.8 \\
\hline 246042.955 & $24_{(9,16)}, v=1$ & $23_{(9,15)}, v=0$ & $1.176 \mathrm{E}-04$ & 343 & 186.0 \\
\hline 246044.081 & $24_{(9,15)}, v=1$ & $23_{(9,14)}, v=0$ & $1.176 \mathrm{E}-04$ & 441 & 186.0 \\
\hline 250230.085 & $19_{(4,15)}, v=0$ & $18_{(3,15)}, v=1$ & $1.043 \mathrm{E}-04$ & 351 & 102.1 \\
\hline 250473.822 & $25_{(4,22)}, v=0$ & $24_{(4,21)}, v=1$ & $1.059 \mathrm{E}-04$ & 357 & 166.5 \\
\hline
\end{tabular}

Notes. ${ }^{(a)}$ Tunnelling is observed between two equivalent equilibrium configurations and splits each rotational level into two distinct states designated $v=0$ and $v=1(\mathrm{BD} 15)$. 


\section{Appendix B: Additional table}

Table B.1. Relative abundances.

\begin{tabular}{lccc}
\hline \hline Component & $\frac{\mathrm{CH}_{3} \mathrm{COOH}}{\mathrm{aGg}^{\prime}\left(\mathrm{CH}_{2} \mathrm{OH}\right)_{2}}$ & $\frac{\mathrm{CH}_{3} \mathrm{COOH}}{\mathrm{gGg}^{\prime}\left(\mathrm{CH}_{2} \mathrm{OH}\right)_{2}}$ & $\frac{\mathrm{aGg}^{\prime}\left(\mathrm{CH}_{2} \mathrm{OH}\right)_{2}}{\mathrm{gGg}^{\prime}\left(\mathrm{CH}_{2} \mathrm{OH}\right)_{2}}$ \\
\hline $8 \mathrm{~km} \mathrm{~s}^{-1}$ & 1.8 & 4.4 & 2.5 \\
\hline $5 \mathrm{~km} \mathrm{~s}^{-1}$ & 2.4 & 5.0 & 2.3 \\
\hline
\end{tabular}

Notes. The given values have uncertainties of $40 \%-50 \%$.

\section{Appendix C: Contamination}

Figure C. 1 shows that the acetic acid emission at $219016 \mathrm{MHz}$ is partially contaminated by the emission from an unidentified species toward the northwest region from the EGP peak.
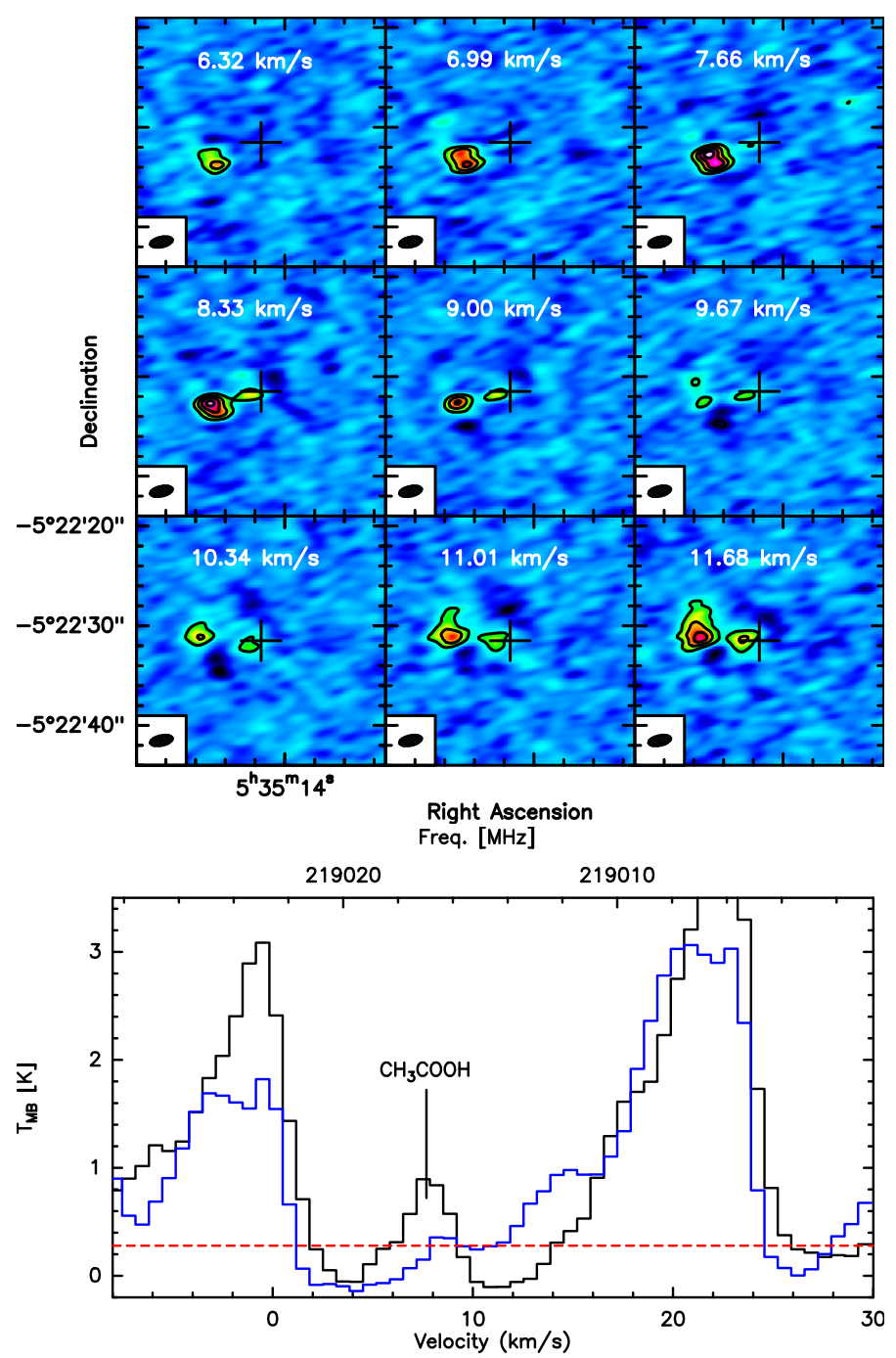

Fig. C.1. Top Panel: $\mathrm{CH}_{3} \mathrm{COOH}$ channel emission maps at 219016 MHz. Bottom Panel: spectra centred at $219016 \mathrm{MHz}$. The black spectrum is taken in direction of the EGP emission peak while the blue one is taken in direction of the northwest clump which contaminates the $\mathrm{CH}_{3} \mathrm{COOH}$ emission maps displayed here as well as in Fig. 1. The red dashed line shows the $3 \sigma$ noise level of the spectrum taken in direction of the northwest clump.

\section{Appendix D: Comparison with the $\mathrm{HCOOCH}_{3}$ emission}

Figure D.1 illustrates the fact the distribution of the emission associated with the acetic acid and the ethylene glycol molecules differs from that of typical O-bearing species, such as methyl formate $\left(\mathrm{HCOOCH}_{3}\right)$ within Orion-KL.

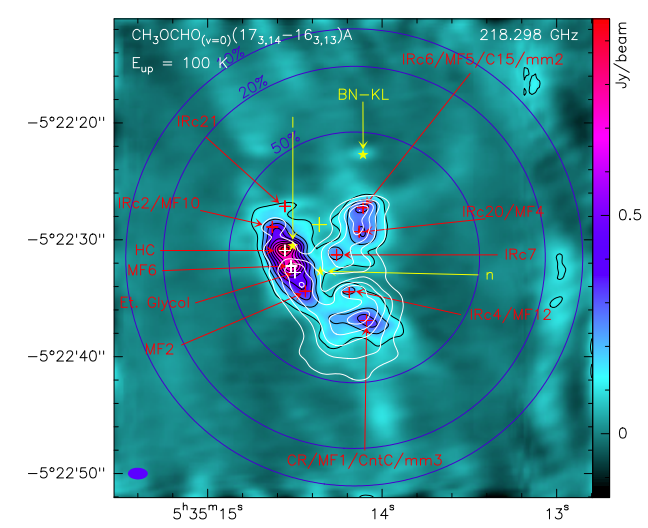

Fig. D.1. Continuum emission at $1.3 \mathrm{~mm}$ (color) overlaid with the $\mathrm{HCOOCH}_{3}$ (write contours) emission at $218298 \mathrm{MHz}$. Positions of the sources analysed in our Paper I are also given. 


\section{Appendix $\mathrm{E}: \mathrm{HC}_{3} \mathrm{~N}$ molecular ring and acetic acid and ethylene glycol emission}

The three panels of Fig. E. 1 show the $\mathrm{HC}_{3} \mathrm{~N}$ ring-like structure emission (Wright \& Plambeck 2017) overlaid with the emission of acetic acid, $\mathrm{aGg}^{\prime}$-ethylene glycol and $\mathrm{gGg}^{\prime}$-ethylene glycol toward the Orion Kleinmann-Low nebula.
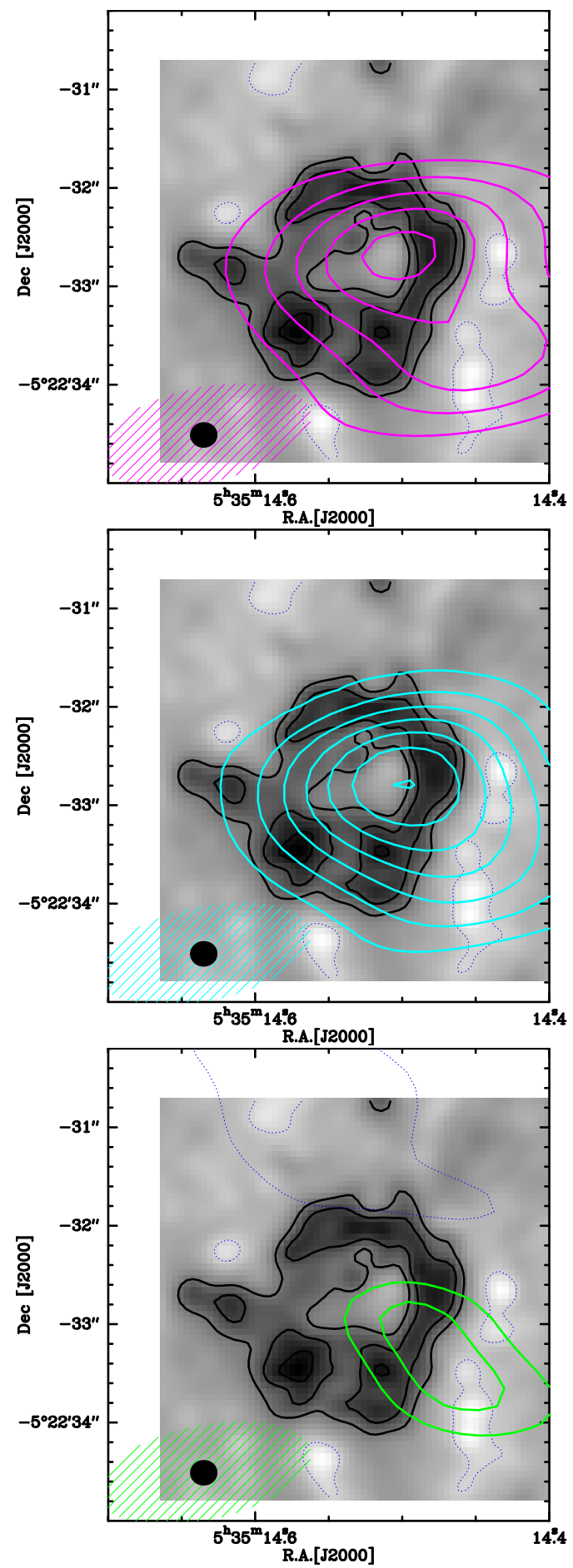

Fig. E.1. ALMA observations of the $\mathrm{HC}_{3} \mathrm{~N}$ emission at $354.69 \mathrm{GHz}$ (in grey scale, see Wright \& Plambeck 2017) overlaid with the emission of acetic acid (purple contours, top panel), aGg'-ethylene glycol (cyan contours, middle panel) and $\mathrm{gGg}^{\prime}$-ethylene glycol (green contours, bottom panel). The ALMA synthesized beams are shown as the black circles for the $\mathrm{HC}_{3} \mathrm{~N}$ data (Wright \& Plambeck 2017) and as colored ellipses for our data. 